\title{
童

\section{UM OLHAR SOBRE AS UNIDADES DE PAISAGEM DA REGIÃO CENTRAL E OESTE DO RIO GRANDE DO NORTE: aspectos importantes da prática de campo na Geografia Física}

\section{A LOOK AT LANDSCAPE UNITS IN THE CENTRAL AND WEST REGION OF RIO GRANDE DO NORTE: important aspects of field practice in Physical Geography}

\section{UNA MIRADA A LAS UNIDADES DE PAISAJE EN LA REGIÓN CENTRAL Y OESTE DE RIO GRANDE DO NORTE: aspectos importantes de la práctica de campo en Geografía Física}

Lisandra dos Santos Bezerra

Graduanda em Geografia pela Universidade Federal do Rio Grande do Norte - UFRN. lisandrastos@gmail.com / http://orcid.org/0000-0002-3829-9656

Brenda Dayane de Souza Faria Cavalcante

Graduada em Pedagogia e discente do Curso de Geografia da Universidade Federal do Rio Grande do Norte - UFRN.

brendafariac@gmail.com / http://orcid.org/0000-0002-8685-8686

\section{Brenda Stéfanie Bezerra}

Graduanda em Geografia pela Universidade Federal do Rio Grande do Norte - UFRN. brendabezerra4@gmail.com / http://orcid.org/0000-0002-3207-0594

\section{Jardielly Faria de Araújo}

Graduada em Geografia da Universidade Federal do Rio Grande do Norte - UFRN. jardiellyyfaria@gmail.com / http://orcid.org/0000-0001-6731-4619

\section{Marco Túlio Mendonça Diniz}

Doutor em Geografia pela Universidade Estadual do Ceará - UECE. Pós-Doutorado no Programa de Pós-Graduação em Geografia da Universidade Federal de Sergipe - UFS. Professor do Departamento de Geografia da Universidade Federal do Rio Grande do Norte - UFRN/CERES. Bolsista de Produtividade em Pesquisa do CNPq. tuliogeografia@gmail.com / http://orcid.org/0000-0002-7676-4475

Recebido: 11/06/2020; Aceito: 11/03/2021; Publicado: 17/08/2021.

\section{RESUMO}

O presente trabalho relata as experiências vivenciadas na região Central e Oeste do estado do Rio Grande do Norte. As atividades em campo ocorreram no âmbito da disciplina Geografia do Rio Grande do Norte, coordenada pelo Prof. Dr. Marco Túlio Mendonça Diniz, na Universidade Federal do Rio Grande do Norte, tendo como objetivo analisar os aspectos geomorfológicos e litológicos das paisagens do estado. Diante do que fora abordado, foi possível obter uma maior compreensão acerca dos aspectos históricos, geológicos, econômicos, físicos, geográficos, geomorfológicos e climatológicos em alguns municípios visitados no Rio Grande do Norte. As áreas visitadas se caracterizaram por serem da depressão sertaneja, planaltos e chapadas, no interior seridoense e oeste, e do litoral setentrional, como as planícies e a Chapada de Serra do Mel. 


\title{
| Seção: Relato de Experiência|
}

| Um olhar sobre as unidades de paisagem da Região Central e Oeste do Rio Grande do Norte: aspectos importantes da prática de campo na Geografia Física |

|Lisandra dos Santos Bezerra | Brenda Dayane de Souza Faria Cavalcante | Brenda Stéfanie Bezerra | Jardielly Faria de Araújo | Marco Túlio Mendonça Diniz |

Ademais, cabe salientar que todo o percurso ocorreu seguindo pelos dois principais rios do Estado. No mais, foi relatada a experiência e importância da atividade.

Palavras-chave: Atividade de Campo; Geocomplexo; Paisagem.

\begin{abstract}
The present report describes the experiences lived in the Central and West regions of the state of Rio Grande do Norte. The field activities took place within the scope of the discipline Geography of Rio Grande do Norte, coordinated by Prof. Dr. Marco Túlio Mendonça Diniz, at the Federal University of Rio Grande do Norte, aiming to analyze the geomorphological and lithological aspects of the state's landscapes. Given what was discussed, it was possible to obtain a greater understanding of the historical, geological, economic, physical, geographic, geomorphological and climatological aspects in some municipalities visited in Rio Grande do Norte. The areas visited were characterized by being from the hinterland depression, plateaus and plateaus, in the interior of the seridense and west, and from the northern coast, such as the plains and the Chapada de Serra do Mel. It is also worth noting that the entire route took place following the two main rivers of the State. In addition, the experience and importance of the activity are reported.
\end{abstract}

Keywords: Field Activity; Geocomplex; Landscape.

\section{RESUMEN}

El presente informe describe las experiencias vividas en las regiones Centro y Oeste del estado de Rio Grande do Norte. Las actividades de campo se llevaron a cabo en el ámbito de la disciplina Geografía de Rio Grande do Norte, coordinada por el Prof. Dr. Marco Túlio Mendonça Diniz, de la Universidad Federal de Rio Grande do Norte, con el objetivo de analizar los aspectos geomorfológicos y litológicos de los paisajes del estado. Dado lo discutido, fue posible obtener un mayor conocimiento de los aspectos históricos, geológicos, económicos, físicos, geográficos, geomorfológicos y climatológicos en algunos municipios visitados en Rio Grande do Norte. Las áreas visitadas se caracterizaron por ser de la depresión del interior, mesetas y mesetas, en el interior de la seridense y oeste, y de la costa norte, como los llanos y la Chapada de Serra do Mel. Cabe señalar también que todo el recorrido se realizó siguiendo los dos ríos principales del Estado. Además, se reporta la experiencia e importancia de la actividad.

Palabras clave: Actividad de Campo; Geocomplejo; Paisaje.

\section{INTRODUÇÃO}

Este relato descreve as atividades de campo realizadas nas regiões Central e Oeste do estado do Rio Grande do Norte no decorrer dos dias 21 a 23 de setembro de 2019. As atividades em campo ocorreram no âmbito da disciplina Geografia do Rio Grande do Norte, no $4^{\circ}$ período do curso de licenciatura em Geografia, sendo desenvolvidas pelo Prof. Dr. Marco Túlio Mendonça Diniz, da Universidade Federal do Rio Grande do Norte. O objetivo do campo foi analisar as unidades de paisagem em seus aspectos geomorfológicos e litológicos. A proposta principal do presente escrito é relatar as experiências vivenciadas pelas autoras na atividade de campo e associar os artigos e discussões realizadas durante a disciplina com as experiências dos ambientes que foram visitados. 
| Um olhar sobre as unidades de paisagem da Região Central e Oeste do Rio Grande do Norte: aspectos importantes da prática de campo na Geografia Física |

|Lisandra dos Santos Bezerra | Brenda Dayane de Souza Faria Cavalcante | Brenda Stéfanie Bezerra | Jardielly Faria de Araújo | Marco Túlio Mendonça Diniz |

As regiões Central e Oeste do estado do Rio Grande do Norte possuem um grande contraste de diferencial de paisagens. Tendo em vista que, a porção central está inserida na depressão sertaneja, a qual compreende áreas majoritariamente aplainadas com exceção da presença de maciços isolados ou relevos de crista (MAIA; BEZERRA, 2014; DINIZ et al., 2017). Essa característica paisagística não mudará tão significativamente ao entrar em contato com o litoral setentrional, visto que, é uma área também extremamente plana e a altitude pouco ultrapassa zero. O diferencial dessa paisagem litorânea será a Chapada de Ponta do Mel, formada pelo soerguimento da Formação Barreiras.

Uma pequena parte da região Oeste do estado também está inserida dentro da depressão sertaneja e possui algumas elevações isoladas, chamadas de planaltos. Esses planaltos abrigam duas cidades que possuem grandes riquezas paisagísticas, bem como um diferente contraste de temperaturas climáticas. Uma vez que, todas as áreas elencadas anteriormente possuem temperaturas climáticas características de áreas semiáridas. Essas, por sua vez, quebram esse paradigma, possuindo sensações climáticas de regiões serranas.

\section{MATERIAIS E MÉTODOS}

A área de estudo está localizada no Rio Grande do Norte, mais precisamente em municípios que compõem as porções norte e oeste do estado. A partir dessa área busca-se entender as mudanças de paisagens que ocorrem desde a depressão sertaneja, seguindo contra o percurso do Rio Piranhas-Açu até o litoral setentrional e, posteriormente, a favor do Rio Apodi-Mossoró, seguindo para os planaltos localizados na depressão do ApodiMossoró. 


\section{|Seção: Relato de Experiência|}

| Um olhar sobre as unidades de paisagem da Região Central e Oeste do Rio Grande do Norte: aspectos importantes da prática de campo na Geografia Física |

|Lisandra dos Santos Bezerra | Brenda Dayane de Souza Faria Cavalcante | Brenda Stéfanie Bezerra | Jardielly Faria de Araújo | Marco Túlio Mendonça Diniz |

Figura 1 - Localização dos trechos visitados com os geocomplexos.

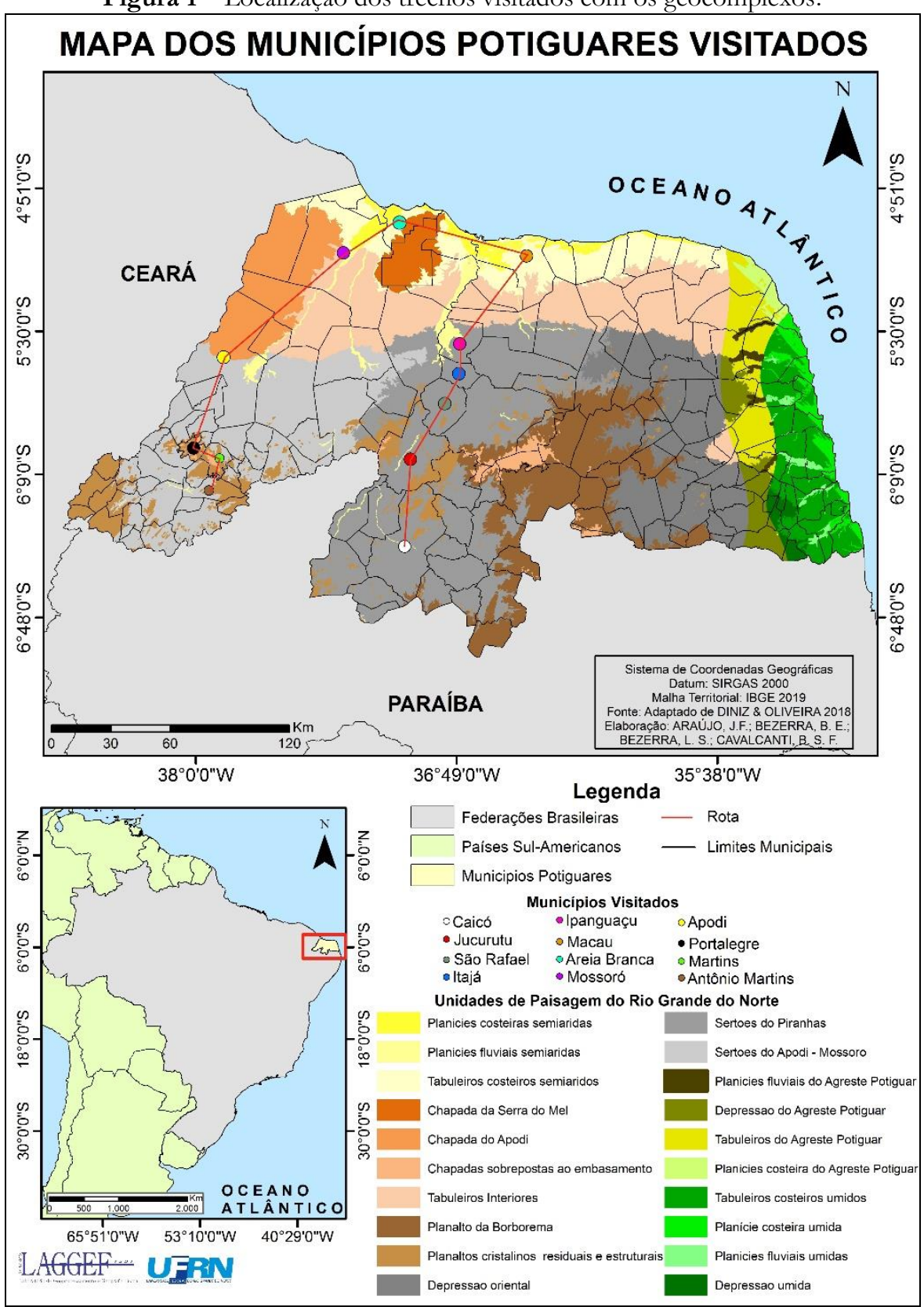

Fonte: Adaptado de Diniz e Oliveira (2018)

Para a produção deste escrito, foi realizado, inicialmente, um levantamento bibliográfico acerca do tema. Para tanto, baseou-se no trabalho elaborado por Diniz e Oliveira (2018), o qual consistiu-se em um mapeamento das unidades de paisagens do estado do Rio Grande do Norte, bem como seus estudos sobre a dinâmica das paisagens, o que correspondeu ao principal ponto norteador para a realização da atividade. Ademais, baseou-se nos conhecimentos adquiridos nas aulas da disciplina de Geografia do Rio Grande do Norte, bem como conhecimentos adquiridos no campo, mediante explicações do docente e observações do meio visitado. 


\section{| Seção: Relato de Experiência |}

| Um olhar sobre as unidades de paisagem da Região Central e Oeste do Rio Grande do Norte: aspectos importantes da prática de campo na Geografia Física |

|Lisandra dos Santos Bezerra | Brenda Dayane de Souza Faria Cavalcante | Brenda Stéfanie Bezerra | Jardielly Faria de Araújo | Marco Túlio Mendonça Diniz |

Portanto, para analisar a dinâmica e organização do que será discutido, os munícipios percorridos para a realização desse trabalho foram: Caicó, Jucurutu, São Rafael, Itajá, Ipanguaçu, Macau e Areia Branca, no primeiro dia. Mossoró, Apodi e Portalegre, no segundo dia. E, Martins e Antônio Martins, no terceiro dia. Percurso descrito na Figura 1.

\section{RESULTADOS E DISCUSSÕES}

O trajeto iniciou-se pela Depressão Sertaneja, onde há extensas áreas rebaixadas e planas, com elevações isoladas constituídas por rochas mais resistentes, estes relevos residuais formam outro geocomplexo que Diniz et al. (2017) caracterizaram como Inselbergs e Campos de Inselbergs.

Para Christofoletti (1973), os Inselbergs são pequenas saliências rochosas que surgiram de soerguimentos de relevos residuais, possuem característica paisagística geralmente de forma dômica, são comumente chamados de "serras" ou "serrotes" dependendo de sua extensão. Essas unidades geomorfológicas representam uma litologia mais resistente na paisagem da depressão, independentemente de estarem ou não cobertos por vegetação. No trajeto foi possível observar algumas dessas formações (Figura 2).

Figura 2 - Mosaico de imagens da área.

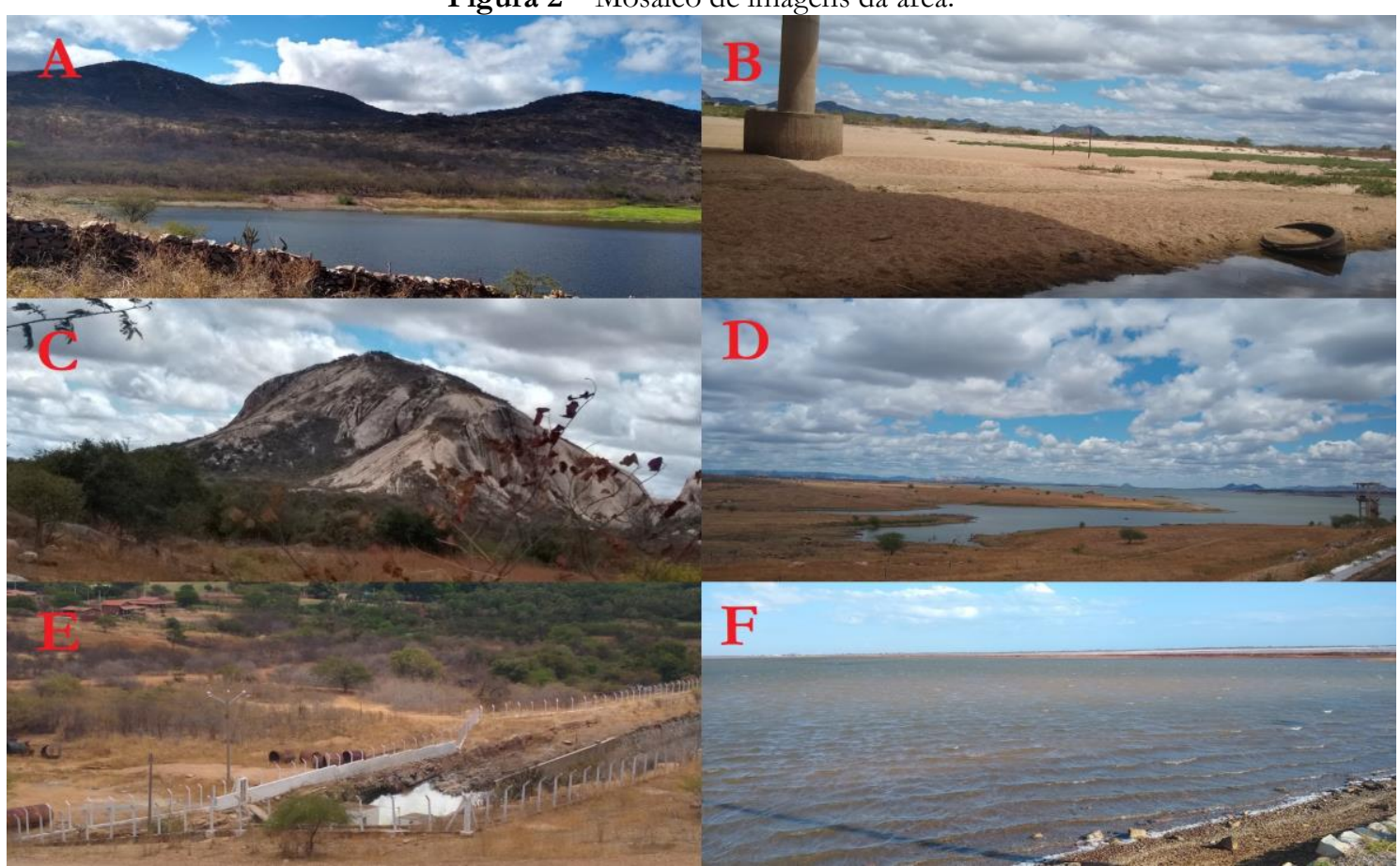

2A- "barreiro" forma histórica de acumular água. 2B- Planície da Bacia Piranhas-Açu. 2C- Afloramento granítico em São Rafael-RN. 2D- Barragem Armando Ribeiro Gonçalves. 2E- Jusante da Barragem Armando Ribeiro Gonçalves. 2F- Tanques de produção de sal marinho. Fonte: acervo dos autores. 


\section{|Seção: Relato de Experiência|}

| Um olhar sobre as unidades de paisagem da Região Central e Oeste do Rio Grande do Norte: aspectos importantes da prática de campo na Geografia Física |

|Lisandra dos Santos Bezerra | Brenda Dayane de Souza Faria Cavalcante | Brenda Stéfanie Bezerra | Jardielly Faria de Araújo | Marco Túlio Mendonça Diniz |

Durante sua formação territorial o sertão seridoense abrigou extensas áreas para monocultura algodoeira. Associado a isso teve também a pecuária extensiva. Ambas as atividades demandaram o extremo uso do solo pelas atividades econômicas, o que causou forte impacto na cobertura e qualidade do solo, visto que, as terras eram utilizadas até se esgotarem e não possuírem mais uso. Em particular, no tocante ao gado, tem-se a criação do gado solto e se alimentava da pastagem natural (COSTA et al., 2009). Assim, ao analisar a paisagem na qual a formação estava contida, é fácil perceber o solo degradado e a presença de um "barreiro", uma forma histórica de acumular água (Figura 2A).

Diniz e Oliveira (2018) dividiram a depressão no Rio Grande do Norte conforme seus divisores de água: na parte central do estado está o geocomplexo Sertões do Piranhas, ou seja, as superfícies deprimidas que drenam as águas da Bacia do Piranhas-Açu se localizam no fundo do vale e na base, estando, assim, perceptível o afloramento rochoso. O vale é plano, caracterizado como geocomplexo planícies fluviais semiáridas, a cada quilômetro percorrido para norte, em direção à costa, a altitude diminui cerca de meio metro (Figura 2B).

O geocomplexo ou complexo geográfico é uma escala de análise geográfica do geossistema. Assim, de acordo com Sochava (1977), o geossistema é uma imaterialização e uma categoria de análise, sendo ele o conceito base e/ou guia para o estudo e análise do geocomplexo.

A drenagem ao convergir para o leito do rio carrega muita sedimentação a cada cheia. Outro motivo para a grande presença de sedimentação, predominantemente arenosa, é a forte energia que o rio possui e pela erosão na área da bacia, que apresenta mata ciliar fragmentada em decorrência de ações antrópicas no espaço.

Em direção a São Rafael, pode-se perceber a mudança na paisagem. $\mathrm{Na}$ área da depressão do Piranhas predominam afloramentos graníticos (Figura 2C), o que dificulta a ocorrência de drenagem fluvial e seu barramento, assim, é um fator limitante para a ocupação humana, em razão do déficit no fornecimento de água. A vegetação mostrou-se bastante preservada, pois foi menos afetada pela ação antrópica ao longo da história do que a área a montante (Seridó Potiguar).

A Barragem Armando Ribeiro Gonçalves, entre os municípios de Açu, São Rafael e Itajá, no Rio Piranhas-Açu, é o maior reservatório de água do estado do Rio Grande do Norte e o segundo maior da região Nordeste do Brasil, apresentando capacidade de aproximadamente 2 bilhões de metros cúbicos. Foi construída na década de 1980 e destinou-se à produção agrícola e, posteriormente, para o abastecimento humano. 


\section{|Seção: Relato de Experiência|}

| Um olhar sobre as unidades de paisagem da Região Central e Oeste do Rio Grande do Norte: aspectos importantes da prática de campo na Geografia Física |

\section{|Lisandra dos Santos Bezerra | Brenda Dayane de Souza Faria Cavalcante | Brenda Stéfanie} Bezerra | Jardielly Faria de Araújo | Marco Túlio Mendonça Diniz |

Ao longo dos anos, o rio foi perenizado artificialmente até sua foz. A barragem supracitada é conhecida por ser considerada um "divisor de mundos", pois a montante da barragem existe o atraso técnico, ou seja, a agricultura e pecuária extensiva (Figura 2D). A jusante acontece a agricultura tecnificada que, em outras palavras, é denominada agricultura globalizada, onde são aplicados investimentos do exterior em uma cultura típica da região tropical, a fruticultura, e após a colheita é realizado o comércio também para o exterior (ALBANO; SA, 2011).

No Vale do Açu, a atividade econômica exercida também é a fruticultura, com cultivo de coco, banana, manga, entre outros, cujas frutas são exportadas. Tal atividade ocorre em virtude do aproveitamento da área, tendo em vista que sempre há água na subsuperfície, pois, apesar de não ser uma região de clima tropical, a atividade é bem consolidada pela presença satisfatória de água subsuperficial. Isso ocorre pelo fato de o Rio Piranhas-Açu abastecer o lençol freático. Assim, a atividade ocorre nas planícies fluviolacustres e nos terraços fluviais.

A caminho do município de Macau a paisagem é marcada por um solo de baixa fertilidade e alta salinidade, apenas com presença escassa de espécies arbustivas pioneiras típicas da caatinga e halófitas herbáceas. A área é extremamente plana e larga, mas já modificada, com a construção de tanques evaporadores para o desenvolvimento da atividade salineira e que hoje alguns deles encontram-se abandonados (MOREIRA DA SILVA; COSTA, 2016). Em termos de classificação, trata-se de uma extensa planície flúvio-marinha que compõe o geocomplexo da planície costeira.

Em Macau, litoral setentrional, o processo de produção do sal marinho é a principal atividade econômica do município e uma das mais importantes do estado. Segundo Diniz e Vasconcelos (2016), a atividade salineira no Brasil ocorre desde o período pré-colonial, quando os nativos consumiam este produto coletado em salinas naturais.

Macau é o município litorâneo mais seco do Brasil, assim, também é considerado um lugar ideal para a produção de sal no estado, uma vez que as suas condições naturais de relevo plano e clima favorável, os altos índices de insolação, baixa média pluviométrica anual e ventos fortes e constantes dão suporte para a alta produtividade de sal. A estação chuvosa acontece apenas nos meses de fevereiro a maio, mesmo assim não prejudica a produção.

A produção do sal marinho acontece em tanques que ficam ao ar livre (Figura 2F). A água fica exposta às condições do tempo, recebendo na maior parte do ano bastante vento e insolação. A água evapora acontecendo a concentração e a cristalização do sal. 


\section{|Seção: Relato de Experiência |}

| Um olhar sobre as unidades de paisagem da Região Central e Oeste do Rio Grande do Norte: aspectos importantes da prática de campo na Geografia Física |

\section{|Lisandra dos Santos Bezerra | Brenda Dayane de Souza Faria Cavalcante | Brenda Stéfanie} Bezerra | Jardielly Faria de Araújo | Marco Túlio Mendonça Diniz |

Seguindo pela Planície Costeira Semiárida, as paisagens das dunas e da chapada em Ponta do Mel são caracterizadas por contrastes de alturas e de cores. Apesar da localidade demonstrar aspectos particulares, são pontos turísticos pouco explorados, em decorrência de seu difícil acesso.

Figura 3 - Mosaico de imagens da área visitada.

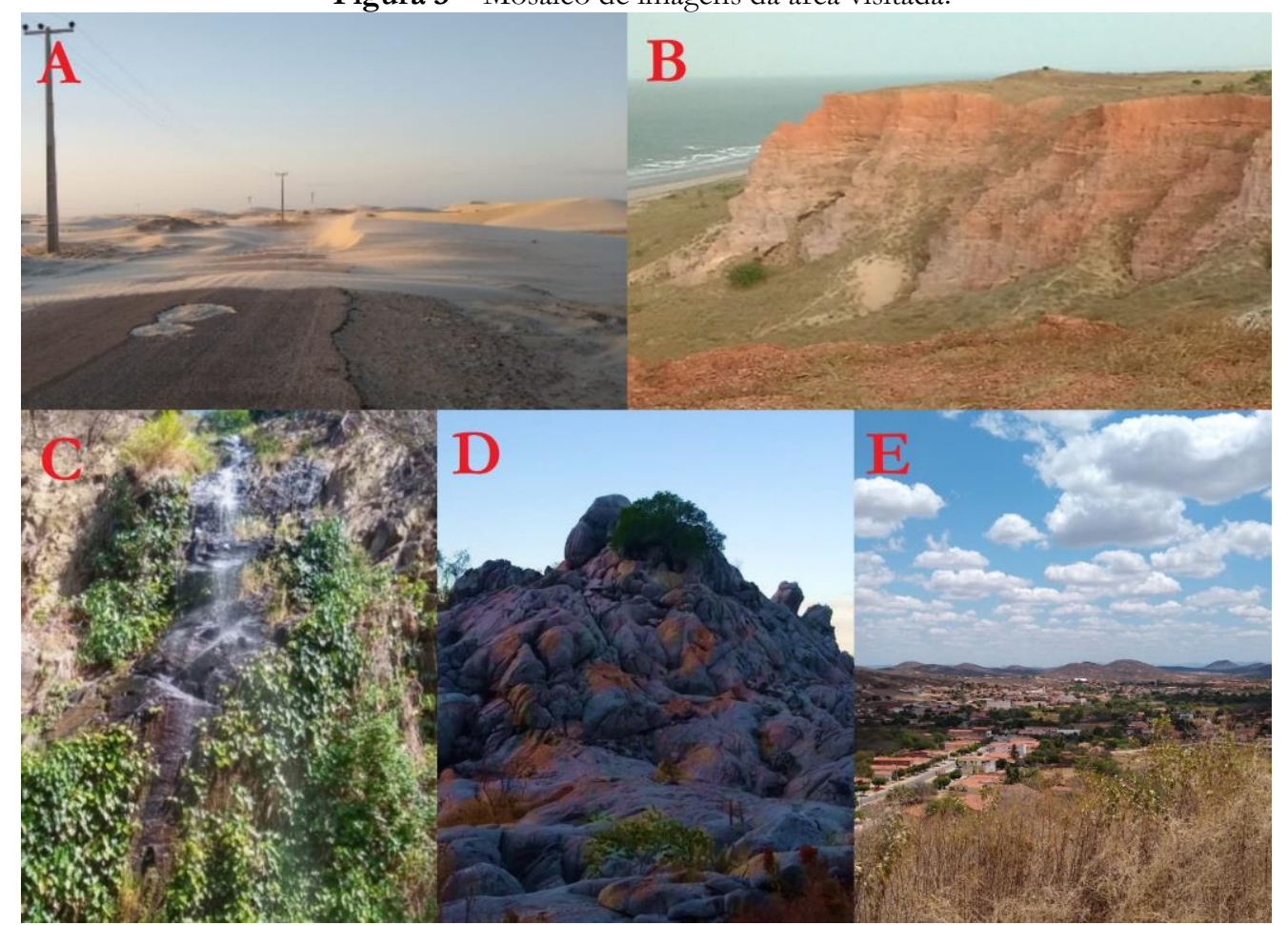

3A- Dunas na rodovia RN-404. 3B- Falésia da Ponta do Mel. 3C- Cachoeira do Pinga em Portalegre-RN. 3D- $2^{a}$ maior afloração de mármore no Brasil. 3E- Depressão do Apodi-Mossoró. Fonte: Acervo dos autores.

As dunas migram em direção a Ponta do Mel (Figura 3A). Esse local é caracterizado pela ocorrência de intensas rajadas de vento provenientes de brisas marítimas, que aumentam no decorrer do aquecimento do continente durante o dia, movimentando as dunas diariamente para o interior, invadindo a rodovia RN-404. As dunas são de coloração bem clara, devido às partículas de areia serem extremamente lavadas pelas águas do mar.

Já a falésia de Serra do Mel corresponde ao que Diniz e Oliveira (2018) caracterizaram de Chapada de Serra do Mel. Essa unidade de paisagem localiza-se em uma escarpa que o tabuleiro semiárido costeiro forma no contato com a planície costeira próximo ao mar. A falésia foi formada pelo soerguimento Grupo Barreiras quando, da formação, formou-se o Domo Salino (MAIA, 2012). A falésia possui um desnível de cerca de 80 metros (Figura 3B).

O município de Mossoró está inserido nos tabuleiros interiores onde, segundo Diniz et al. (2017), o relevo é aplainado e evoluiu sobre os arenitos e calcários. Essa rocha 
|Lisandra dos Santos Bezerra | Brenda Dayane de Souza Faria Cavalcante | Brenda Stéfanie Bezerra | Jardielly Faria de Araújo | Marco Túlio Mendonça Diniz |

possui diversidade para sua utilidade como, por exemplo, a produção de paralelepípedos utilizados em ruas das cidades posicionadas sobre a Bacia Potiguar.

No que diz respeito à ocupação humana sobre os tabuleiros interiores do estado, é muito rarefeita e a vegetação bastante conservada. As áreas mais elevadas dos tabuleiros são aproveitadas para a produção de energia eólica. Esse déficit da ocupação humana é em decorrência da escassez hídrica, pois, com exceção dos rios Apodi-Mossoró e Açu, não há outra fonte de água próxima à superfície na área.

O Lajedo Soledade, sítio arqueológico localizado no distrito de Soledade, município de Apodi, tem área de cerca de dois quilômetros quadrados de rocha calcária exposta, apresenta variedade em grutas, fendas profundas e cavernas. O município de Apodi está inserido no que Diniz e Oliveira (2018) caracterizaram de Chapada do Apodi, integrando o tabuleiro semiárido interiorano, conforme os autores citados. A chapada está em forma de rampa suave e são formadas pelo calcário Jandaíra (DINIZ; OLIVEIRA, 2018).

Conforme Maia (2012), a cerca de 90 milhões de anos essa área era coberta por um mar raso que, a partir de seu recuo, revelou essa grande extensão de rocha calcária. O lajedo de calcário sofreu ao longo dos tempos dissolução dessa rocha e erosões provocadas por fatores naturais, como a ação pluvial e fluvial, dessa forma, originando relevo cárstico, que contém cavernas e fendas.

A trilha demarca três distintas áreas: a primeira é a denominada de Urubu, por conter formações rochosas escuras e pontiagudas, além da presença de algumas cavernas; segunda foi chamada de Araras, por existir a presença de inúmeras gravuras; por fim, a última foi chamada de Olho D’água, por apresentar no período chuvoso da região em seus afloramentos rochosos um acúmulo de água.

No município de Portalegre, Oeste Potiguar, foi visitada a Cachoeira do Pinga, uma área natural, subindo o planalto interior. Portalegre faz parte do planalto cristalino residual e estrutural com sedimentos sobrepostos ao embasamento (DINIZ; OLIVEIRA, 2018). Essa área apresenta maior altitude, com cerca de 700 metros e, consequentemente, menores temperaturas em relação à depressão do Apodi-Mossoró que rodeia esse planalto. O local visitado apresenta um riacho quase perene, proveniente da água que vem do arenito e aflora na cachoeira (Figura 3C).

$\mathrm{Na}$ referida localidade, a vegetação é mais presente, a qual predomina fitofisionomias de Caatinga arbórea, além de um enclave de Mata Atlântica (GUEDES, 2016), apresentando troncos altos e retilíneos como resposta evolutiva à competição por luz solar. Vale frisar que, por consequência, a presença das espécies provenientes do bioma 


\section{|Seção: Relato de Experiência|}

| Um olhar sobre as unidades de paisagem da Região Central e Oeste do Rio Grande do Norte: aspectos importantes da prática de campo na Geografia Física |

|Lisandra dos Santos Bezerra | Brenda Dayane de Souza Faria Cavalcante | Brenda Stéfanie Bezerra | Jardielly Faria de Araújo | Marco Túlio Mendonça Diniz |

Mata Atlântica caracteriza o Maciço de Martins/Portalegre como um brejo de altitude (ANDRADE-LIMA, 1982 apud PRADO, 2003).

A Casa de Pedra é um monumento lendário da Serra de Martins. Todo o afloramento rochoso é de mármore, que é um calcário metamorfizado. O mármore possui uma dissolução mais lenta, assim, suas formações no interior são muito antigas. Como ele ficou bastante conservado, a dissolução criou uma caverna no seu interior, com estalactites, estalagmites e colunas. A área possui potencial para o geoturismo, com capacidade de atrair visitação. No interior possui diversos salões, cada local nomeado como um compartimento de uma casa. Na parte final da Casa de Pedra foi possível conhecer o vislumbre de vista com a segunda maior afloração de mármore do Brasil (Figura 3D).

Por estar situada em altitudes elevadas, as precipitações e temperaturas se diferem das citadas anteriormente. Assim, esse ponto, tem precipitações acima de $800 \mathrm{~mm}$ ao ano e a temperatura bem agradável durante o dia, e a noite ficando pouco abaixo de $20^{\circ} \mathrm{C}$. A vegetação aproveitou os sumidouros, que são orifícios naturais ou artificiais por onde um curso d'água passa e penetra no solo, e assim se adaptou e cresceu entre as rochas de mármore, conhecido como inselbergs vegetados.

A cidade de Martins no período do século XIX era considerada uma das três vilas mais importantes do estado do Rio Grande do Norte, sendo a terceira comarca do estado do RN por causa de seu elevado nível de desenvolvimento em comparação com a então vila de Portalegre que era a mais antiga da região oeste.

Essa cidade teve como fator importante para o seu desenvolvimento a vasta capacidade na produção de alimentos no contexto regional, que é de clima semiárido, de modo que existia uma policultura de alimentos provenientes da elevada capacidade hídrica do arenito Serra do Martins em reter água em subsuperfície, sendo implantado frutíferas como, jaqueira, mangueira, entre outros que substituíram a vegetação original. Essa policultura gerava um significativo comércio. Em Martins, uma paisagem de exceção com chuvas médias acima dos $1000 \mathrm{~mm} /$ ano e latossolos profundos bastante utilizados na produção de gêneros agrícolas alimentícios.

O termo "paisagem de exceção" foi estudado por Ab’Saber (2003) no qual definiu como sendo fatos isolados, de diferentes aspectos físicos e ecológicos inseridos no corpo geral das paisagens habituais. Para tanto, Ab’Saber (2003) classificou diferentes paisagens de exceção existentes no Brasil, dentre elas, tem-se: os pontões rochosos, canyons brasileiros, agrupamento de inselbergs, topografias ruiniformes, dentre outros. Assim, a paisagem de exceção existente em Martins é justamente por ser uma área com amenidade 
| Um olhar sobre as unidades de paisagem da Região Central e Oeste do Rio Grande do Norte: aspectos importantes da prática de campo na Geografia Física|

|Lisandra dos Santos Bezerra | Brenda Dayane de Souza Faria Cavalcante | Brenda Stéfanie Bezerra | Jardielly Faria de Araújo | Marco Túlio Mendonça Diniz |

no clima e bom solo para a atividade agrícola frutífera, no meio de toda a depressão Sertões do Apodi-Mossoró (DINIZ; OLIVEIRA, 2018).

O decréscimo econômico da região ocorreu quando se implantou a monocultura do algodão no sertão, pois os sertanejos que antes deslocavam-se para Martins, para obter os alimentos ali produzidos, não necessitavam mais dessa prática. Percebe-se que hoje uma das atividades econômicas principais da cidade é o turismo, com atrativos relacionados ao clima agradável serrano entrando em contraste com o clima semiárido dos demais municípios do interior do estado do Rio Grande do Norte.

O município de Antônio Martins está inserido na depressão do Sertão ApodiMossoró e ao redor do município existem vários planaltos cristalinos e residuais (DINIZ; OLIVEIRA, 2018), podendo ser visualizados na Figura 3E. Segundo Diniz et al. (2017), trata-se de extensas superfícies aplainadas onde a monotonia do relevo baixo só é quebrada com a ocorrência de elevações isoladas, que em sua maioria são as rochas mais resistentes ao processo erosivo. Assim, exibe um relevo bastante movimentado, com superfícies onduladas e íngremes de solo profundo e avermelhado, característico do tipo argissolo, o que propicia condições para o estabelecimento de estrato de vegetação arbórea (GUEDES, 2016).

Ademais, sabe-se que a ciência geográfica estuda todo o espaço geográfico, ou seja, isso inclui tanto os fatores bióticos como abióticos. De acordo com Souza e Pereira (2016), o trabalho de campo é um instrumento didático e que é amplamente usado por professores e principalmente dentro do âmbito da Geografia. Ainda segundo Souza e Pereira (2016), trabalho de campo é entendido como qualquer atividade investigativa e/ou exploratória, permitindo sair da rotina e proporcionar uma experiência extrassala. Conforme Callai et al. (1988), durante o tempo em que se desenvolve o trabalho de campo, o professor deve ter o zelo de situar a atividade que está em desenvolvimento, evitando o "fazer por fazer". Dessa forma, a execução de estudos práticos in loco é de fundamental importância e necessidade para o geógrafo. Pois, é a partir da experiência no local que os estudos previamente realizados são devidamente confirmados ou contestados. Além disso, é a partir do campo que novas perspectivas são criadas.

\section{CONSIDERAÇÕES FINAIS}

Dado o exposto, o relato descreveu as atividades realizadas nas áreas Central e Oeste do estado. A experiência da aula de campo oportunizou uma consolidação dos 
| Um olhar sobre as unidades de paisagem da Região Central e Oeste do Rio Grande do Norte: aspectos importantes da prática de campo na Geografia Física|

|Lisandra dos Santos Bezerra | Brenda Dayane de Souza Faria Cavalcante | Brenda Stéfanie Bezerra | Jardielly Faria de Araújo | Marco Túlio Mendonça Diniz |

conhecimentos prévios já obtidos em um momento anterior, durante as aulas da disciplina Geografia do Rio Grande do Norte e estudos prévios das bibliografias, assim como a aquisição de novos saberes que muito contribuem para com a nossa aprendizagem. A partir desta experiência foi possível observar o quão vasta é a organização paisagística do estado. Com recursos proporcionados pela universidade, como ônibus, motorista e afins, bem como recursos próprios das estudantes para alimentação e pernoites, foram três dias intensos e com ganhos satisfatórios.

Para tanto, a Geografia estuda todos os espaços e parâmetros, logo, ressaltamos a importância da aula de campo para os estudantes de Geografia. De fato, uma aula de campo bem preparada e organizada é um instrumento didático que proporciona conhecimentos únicos, que nenhum livro ou imagem pode viabilizar. Assim, de modo claro e dinâmico foi possível obter uma maior compreensão acerca dos aspectos descritos ao longo do texto. Por fim, espera-se que este breve relato sirva de orientação ou instrução para buscas de informações voltadas tanto para o turismo como meio de pesquisas para os estudantes de Geografia do estado.

\section{REFERÊNCIAS}

AB'SÁBER, A. N. Os Domínios de Natureza no Brasil: potencialidades paisagísticas. São Paulo, SP: Ateliê Editorial, 2003.

ALBANO, G. P.; SA, A. J. Globalização da Agricultura: multinacionais no campo brasileiro. Terra Livre, v. 1, p. 126-151, 2011.

CALLAI, H. C. [et al.]. O estudo do município e o ensino de história e geografia. Ijuí: Unijuí, 1988.

COSTA, T. C. C.; OLIVEIRA, M. A. J.; ACCIOLY, L. J. O.; SILVA, F. H. B. B. Análise da degradação da caatinga no núcleo de desertificação do Seridó (RN/PB). Revista Brasileira de Engenharia Agrícola e Ambiental, v. 13, p. 961-974, 2009.

CHRISTOFOLETTI, A. As Teorias Geomorfológicas. Notícia Geomorfológica, Campinas, v. 13, n. 25, 1973.

MOREIRA DA SILVA, D. E.; COSTA, D. F. S. Classificação das áreas úmidas (AUs) hipersalinas da bacia hidrográfica do Rio Piancó-Piranhas-Açu e da Faixa Litorânea Norte de Escoamento Difuso. Revista de Geociências do Nordeste, v. 2, p. 1436-1446, 2016.

DINIZ, M. T. M. [et al.]. Mapeamento Geomorfológico do Estado do Rio Grande do Norte. Revista Brasileira de Geomorfologia, São Paulo, v. 18, n. 4, p. 689-701, dez. 2017. Disponível em: < http://dx.doi.org/10.20502/rbg.v18i4.1255>. Acesso em: 18 maio 2020. 
|Um olhar sobre as unidades de paisagem da Região Central e Oeste do Rio Grande do Norte: aspectos importantes da prática de campo na Geografia Física |

|Lisandra dos Santos Bezerra | Brenda Dayane de Souza Faria Cavalcante | Brenda Stéfanie Bezerra | Jardielly Faria de Araújo | Marco Túlio Mendonça Diniz |

DINIZ, M. T. M.; OLIVEIRA, A. V. L. C. Mapeamento das Unidades de Paisagem do estado do Rio Grande do Norte, Brasil. Boletim Goiano de Geografia, v. 38, n. 2, p. $342-$ 364, maio/ago. 2018. Disponível em: < https://doi.org/10.5216/bgg.v38i2.54613 >. Acesso em: 18 maio 2020.

DINIZ, M. T. M.; VASCONCELOS, F. P. Aspectos históricos e locacionais da economia salineira brasileira. Boletim Gaúcho de Geografia (Online), v. 43, n. 1, p. 121-146, 2016. Disponível em: <https://seer.ufrgs.br/bgg/article/view/53882>. Acesso em: 18 maio 2020.

GUEDES, J. C. F. Comparação de índices de vegetação no mapeamento da cobertura da terra no semiárido: estudo de caso no Município de Martins/RN. 2016. 87 p. Dissertação (Mestrado em Geografia) - Centro de Ciências Humanas, Letras e Artes. Natal-RN: Universidade Federal do Rio Grande do Norte, 2016.

MAIA, R. P.; BEZERRA, F. H. R. Tópicos de geomorfologia estrutural: Nordeste brasileiro. Fortaleza: Edições UFC, 2014. 124 p.

MAIA, R. P. Geomorfologia e neotectônica no vale do rio Apodi-Mossoró RN. 2012. 218 f. Tese (Doutorado em Geodinâmica) - Programa de Pós-Graduação em Geodinâmica e Geofísica, Universidade Federal do Rio Grande do Norte, Natal, 2012.

PRADO, D. E. As caatingas da América do Sul. In: LEAL, I. R.; TABARELLI, M.; SILVA, J. M. C. (Org.). Ecologia e conservação da Caatinga. Recife: Ed. Universitária da UFPE, 2003. p. 3-74.

SOCHAVA, V. B. O estudo de geossistemas: métodos em questão. São Paulo: Instituto de Geografia/USP, 1977. 51 p.

SOUZA, J. C.; PEREIRA, R. M. Uma reflexão acerca da importância do trabalho de campo e sua aplicabilidade no ensino de Geografia. 2016. Disponível em: $<$ https://files.cercomp.ufg.br/weby/up/215/o/uma reflexao acerca da importancia do trabalho de campo.pdf>. Acesso em: 20 mar. 2021.

Como citar este relato de experiência:

\section{ABNT}

BEZERRA, L. S. [et al.]. Um olhar sobre as unidades de paisagem da Região Central e Oeste do Rio Grande do Norte: aspectos importantes da prática de campo na Geografia Física. InterEspaço: Revista de Geografia e Interdisciplinaridade, v. 7, e202116, 2021. Disponível em: <http://dx.doi.org/10.18764/2446-6549.e202116>. Acesso em: 17 ago. 2021.

\section{APA}

Bezerra, L. S. [et al.]. Um olhar sobre as unidades de paisagem da Região Central e Oeste do Rio Grande do Norte: aspectos importantes da prática de campo na Geografia Física. 
| Um olhar sobre as unidades de paisagem da Região Central e Oeste do Rio Grande do Norte: aspectos importantes da prática de campo na Geografia Física|

|Lisandra dos Santos Bezerra | Brenda Dayane de Souza Faria Cavalcante | Brenda Stéfanie Bezerra | Jardielly Faria de Araújo | Marco Túlio Mendonça Diniz |

InterEspaço: Revista de Geografia e Interdisciplinaridade, v. 7, e202116. Recuperado em 17 agosto, 2021, de http://dx.doi.org/10.18764/2446-6549.e202116

\section{@creative}

This is an open access article under the CC BY Creative Commons 4.0 license.

Copyright (C) 2021, Universidade Federal do Maranhão.

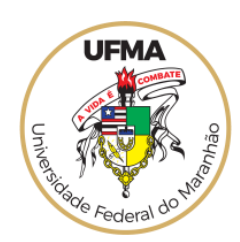

